ANUARIO MUSICAL, N. ${ }^{\circ} 66$

enero-diciembre 2011, 181-202

ISSN: 0211-3538

\title{
Polémicas wagnerianas en el Siglo XIX en EsPaña
}

\author{
Wagnerian Controversies in Spain in 19th CENTURY
}

\author{
José Ignacio Suárez García \\ Universidad de Oviedo
}

\section{Resumen:}

En la década de 1860 la crítica musical española plantea una oposición sobre la validez estética de dos sistemas considerados excluyentes: la ópera italiana y el drama musical wagneriano. Este antagonismo provocará en la década posterior la aparición de polémicas que abordan, entre otros temas, el papel que en el drama lírico deben desempeñar texto, música, cantante, orquesta, melodía y armonía. Aunque con el debate estético siempre como telón de fondo, las querellas están motivadas y son catalizadoras de intereses editoriales, enfrentamientos nacionalistas, rencillas personales y choques generacionales. En el presente trabajo hacemos un repaso diacrónico de estas discusiones, en las que la controvertida personalidad del compositor alemán es un factor negativamente determinante.

\section{Palabras clave:}

Richard Wagner, (Recepción, Polémicas, España); La España Musical. Andrés Vidal y Roger; José Castro y Serrano; José Pujol Fernández; José Piqué y Cerveró; Francisco A. Barbieri; Antonio Peña y Goñi; Joaquín Marsillach Lleonart; Antonio Fargas y Soler.

\begin{abstract}
:
Spanish musical criticism raises in the 1860s an objection on the validity in two systems considered exclusive: Italian opera and Wagnerian music drama. In the next decade this antagonism will result the emergence of controversies that address, among other issues, the role that in the lyric drama must play text, music, singer, orchestra, melody and harmony. Although with the aesthetic debate forever as a backdrop, the controversies are motivated and are catalysts for publishing interests, nationalist clashes, personal quarrels and generation clashes. In this article we review diachronically these discussions, in which the controversial German composer's personality is a determinant factor negatively.
\end{abstract}

\section{Keywords:}

Richard Wagner, (Reception, Controversial, Spain); La España Musical. Andrés Vidal y Roger; José Castro y Serrano; José Pujol Fernández; José Piqué y Cerveró; Francisco A. Barbieri; Antonio Peña y Goñi; Joaquín Marsillach Lleonart; Antonio Fargas y Soler. 
A lo largo de la década de 1860 la crítica musical española contrapone las escuelas de ópera italiana y alemana, considerando a Wagner como un compositor radical que, erigido en máximo representante de la peyorativamente denominada "escuela pintoresca", es, al mismo tiempo, inventor de la llamada música del porvenir. La discusión, expuesta frecuentemente como belcantismo versus wagnerismo, se plantea por oposición de contrarios, presentando antagónicamente los términos inspiración-cálculo, genio-ingenio, melodía-armonía, idealismo-realismo, espontaneidad-estudio, expresión-efectos, forma cerrada-abierta, fraseo regular-irregular, modulación natural-antinatural, predominio de la parte vocalinstrumental, sentimiento-razón... y otros ${ }^{1}$. Si para los partidarios de la escuela italiana la función esencial de la música es deleitar al oído, para Wagner la música debe secundar al texto con el fin de reforzar su verosimilitud dramática y convertirse, así, en un elemento más de la obra de arte total. En este sentido, se oponen una visión autónoma de las artes con la proposición wagneriana de Gesamkunstwerk, cuya concepción lleva inmanente la idea de que el error fundamental y tradicional de la ópera había consistido en convertir un medio de expresión (la música) en un fin, y éste (el drama), en un medio. Así, superando las formas tradicionales y mediante el empleo del leitmotiv, Wagner organiza el discurso en amplias escenas que prescinden de la característica separación entre recitativo y aria y, simultáneamente, reestructura las funciones musicales encomendando a la orquesta la misión de explicar el estado anímico del personaje, al tiempo que el cantante queda incluido en la red de comunicación y motivación del conjunto. Su idea de drama musical se aleja, por tanto, del simple disfrute sensorial y auditivo, exigiendo al espectador una preparación previa sin precedentes en la historia de la ópera, un aspecto que, junto a su novedosa armonía e instrumentación, son los más censurados por críticos como Vicente Cuenca, José Parada y Barreto y Óscar Camps y Soler.

Hemos tratado en otro lugar los principales puntos de discusión estéticos surgidos en España tras la década de 1860 (unión texto-música en el drama lírico, su forma, la relación de la música con otras artes, el papel que desempeñan cantante y orquesta, melodía y armonía... $)^{2}$, así como las analogías y divergencias estéticas existentes entre wagnerismo y krausoinstitucionismo ${ }^{3}$, por lo que en el presente trabajo nos proponemos abordar prioritariamente el desarrollo diacrónico de las polémicas, entendiendo por tales, aquéllas en las que explícitamente se produce una sucesión de argumentación-réplica entre, al menos, dos interlocutores, prescindiendo de dar cuenta del numeroso corpus de escritos producidos en España en el siglo XIX sobre el tema que no son contestados por ningún polemista.

1 Véase SuÁrez, José Ignacio: “La recepción de la obra de Richard Wagner en Madrid entre 1861 y 1876”, en Cuadernos de Música Iberoamericana, 10 (2005), pp. 71-96.

2 Véase SuÁrez, José Ignacio: “La recepción de la obra de Richard Wagner en Madrid entre 1877 y 1893 ”, en Cuadernos de Música Iberoamericana, 14 (2007), pp. 73-142.

3 SuÁrez García, José Ignacio: “Krausoinstitucionismo y wagnerismo”, en Nassarre, 25 (2009), pp. 55-70. 


\section{POLÉMICAS EN TORNO A LOS ESTRENOS WAGNERIANOS EN ITALIA (1871-1873)}

Surgidas a raíz de los primeros estrenos wagnerianos realizados en Italia, hay que esperar a principios de la década de 1870 para que se inauguren las polémicas de este tipo en nuestro país. Tratan tangencialmente el debate estético y están motivadas principalmente por razones económicas, ya que el representante de las obras de Wagner en Italia, el editor de Milán Francesco Lucca, es al mismo tiempo socio de la casa barcelonesa de Andrés Vidal y Roger. La España Musical, revista propiedad de Vidal y Roger, juega un papel determinante ya que, convertida en portavoz del wagnerismo, defenderá estas representaciones y los intereses editoriales de Lucca y Vidal ${ }^{4}$.

1871 es un año clave por varios motivos. En primer lugar, surgen los primeros roces entre La España Musical y El Correo de Teatros, semanario defensor de la escuela italiana y muy crítico con Wagner ${ }^{5}$. En segundo lugar, La España Musical realiza una declaración de intenciones wagneriana para defender abiertamente al compositor, aún consciente de que este propósito es -según manifiesta- "más arduo, más difícil, mucho más expuesto que pronunciar un discurso en defensa de la Comunne" ${ }^{" 6}$. En tercer lugar, porque el 1 de noviembre el Teatro Comunal de Bolonia presenta Lohengrin, el primer estreno wagneriano en Italia, nacionalidad musical presentada como antítesis de la reforma wagneriana.

Hacía meses que Lucca había ideado en Italia la representación de Lohengrin, estrenado bajo la dirección de Angelo Mariani y con Italo Campanini ${ }^{7}$ en el papel protagonista ${ }^{8}$. En la división producida en la opinión pública italiana, destaca por su antiwagnerismo el periódico L'Affondatore de Bolonia, que mantendrá una viva polémica pocos meses después con La España Musical. Ésta destaca el éxito de la primera representación ${ }^{9}$ y cómo esta premier es considerada por los antiwagnerianos como un insulto al arte dramático italiano ${ }^{10}$. También Antonio Peña y Goñi muestra su complacencia por la acogida de Lohengrin en el "país del bel canto", comentando con sarcasmo "si los italianos padecen tal vez un momentáneo acceso de enajenación mental" ". Malinterpretados los comentarios de Peña, el Diario Español publica un durísimo suelto ${ }^{12}$ con la intención de provocar una polémica en la que Peña aclara que su escrito "fue inspirado por la satisfacción que sentimos al saber que la obra maestra de Wagner había

4 Vidal vende la reducción para canto y piano de El Holandés errante, Tannhäuser y Lohengrin, al menos, desde marzo de 1869 [“Andrés Vidal y Roger, Editor. Extracto del catálogo general”, en La España Musical, iv/162 (18.03.1869), p. 4]. Además en 1870 solicita a Wagner la publicación de alguna partitura que, conservadas en primera instancia por su hijo, Andrés Vidal y Llimona, no han sido localizadas hasta la fecha (Véase JANÉs I NADAL, Alfonsina: L'obra de Richard Wagner a Barcelona. Barcelona, Rafael Dalmau, 1983, p. 26).

5 Sorprendida, la revista de Vidal pide explicaciones sobre si este "ataque" a la "escuela reformista" forma parte de la profesión de fe de El Correo de Teatros. "Revista teatral”, en La España Musical, vi/244 (23.02.1871), p. 4.

6 OpISso, Antonio: "Confiteor”, en La España Musical, vi/263 (13.07.1871), pp. 3-4.

7 Campanini consideró este estreno como el más relevante de su carrera artística. "Italo Campanini”, en La Ilustración Musical, I/15 (14.07.1883), p. 2.

8 "Noticias", en La España Musical, vi/278 (26.10.1871), p. 7.

9 “Noticias", en La España Musical, vi/281 (16.11.1871), p. 7.

10 Perraccio, L.: "Primera representación del Lohengrin de Wagner en Italia”, en La España Musical, vi/282 (23.11.1871, pp. 1-2) y 283 (30.11.1871, pp. 1-2).

11 "Sección de Espectáculos", en El Imparcial, 28.11.1871.

12 Diario Español, 29.11.1871. 
obtenido gran éxito"13. El crítico donostiarra zanja la querella no sin antes hacer algunas observaciones al "gacetillero del Diario Español"14.

Alentados por el extraordinario éxito de Lohengrin, en enero de 1872 se anuncia el próximo estreno de Tannhäuser en el Teatro Comunal. A este proyecto, criticado por el periódico milanés Il Trovatore, se suma la preparación de una gira organizada por Lucca para dar a conocer Lohengrin en las principales ciudades italianas ${ }^{15}$. A pesar de la oposición del consejo municipal de Bolonia ${ }^{16}$, el 7 de noviembre de 1872 se estrena Tannhäuser bajo la dirección de Mariani y con Gayarre en el papel protagonista. En la escandalosa primera representación se pasa de los tímidos silbidos y murmullos, a una verdadera protesta en la que el tumulto es completo, retirándose el público agitadamente ${ }^{17}$. La prensa antiwagneriana se regodea describiendo los silbidos y burlas producidos ${ }^{18}$, así que, indignada ante el fiasco -preparado y organizado premeditadamente según La España Musical ${ }^{19}$ - la revista barcelonesa reta a Gazzetta Musicale de Milano, Gazzetta de Trevisso, l'Opinione y Dietro le Scene a debatir sobre el mérito de la partitura ${ }^{20}$, convencida de que los argumentos de las publicaciones italianas son producto de un "amor propio exagerado"21. Pocos días después del estreno fallece Francesco Lucca $^{22}$, mientras distintos periódicos felicitan a La España Musical por el reto planteado a los rotativos citados ${ }^{23}$.

Contestan sin hacer argumentación crítica la Gazzetta Musicale de Milano, el periódico boloñés Dietro le Scene $e^{24}$ y L'Affondatore que, tomando en serio un humorístico suelto anunciando el estreno de Tannhäuser en Barcelona, le vaticina el mismo éxito que el obtenido en Italia ${ }^{25}$. Asimismo, L'Affondatore acusa a la revista de Vidal de convertirse en una sucursal de la casa Lucca y critica su marcada predilección hacia la escuela moderna alemana. También afirma que Tannhäuser carece de mérito porque está equivocado en argumento y música, de forma que sería necesario renovarlo en su totalidad. La España Musical considera imposible debatir si no se proponen otros razonamientos y, también, que la oposición de L'Affondatore es fruto del encono y ofuscamiento nacionalista con que ve la reforma wagneriana.

Una controvertida opinión publicada en La España Musical sobre la decadencia de la escuela italiana -en el sentido de que tras Rossini, Donizetti, Bellini... no puede mantenerse únicamente con Verdi- hiere susceptibilidades, trasladándose el debate hacia el mérito de los compositores de sendos países. L'Affondatore asegura que España aún no ha tenido ningún maestro de fama y, en doloroso y certero análisis, recuerda que el repertorio escuchado en los teatros españoles es fundamentalmente italiano.

13 [PeÑa y GoÑI, Antonio]: "Sección de Espectáculos”, en El Imparcial, 30.11.1871.

14 [PeÑa y GoÑI, Antonio]: "Sección de Espectáculos”, en El Imparcial, 01.12.1871.

15 "Noticias", en La España Musical, viI/289 (11.01.1872), p. 4.

16 "Noticias", en La España Musical, viI/309 (16.05.1872), p. 7.

17 "Noticias", en La España Musical, viI/334 (01.12.1872), p. 7.

18 "Noticias", en La España Musical, vII/333 (24.11.1872), p. 8.

19 Cuspinera, Clemente: "Wagner, según el médico Puschmann", en La España Musical, viII/342 (25.01.1873), p. 2.

20 "Advertencia", en La España Musical, viI/334 (01.12.1872), p. 1.

21 "Wagner en Italia”, en La España Musical, viI/338 (29.12.1872), p. 3.

22 La España Musical, vII/334 (01.12.1872), p. 5.

23 La España Musical, vII/336 (15.12.1872), p. 3.

24 "Wagner en Italia”, en La España Musical, viI/338 (29.12.1872), p. 3.

25 La España Musical, vII/334 (01.12.1872), p. 6. 
Por último, insiste en que la música de Wagner no se aclimatará en nuestro país porque el empeño de $L a$ España Musical no responde a una mayoría, sino a intereses particulares. La revista barcelonesa contesta criticando el escaso valor de muchas óperas italianas coetáneas y, asimismo, que la costumbre de representar repertorio italiano prueba solamente que "aún no se ha formado en España por completo el buen gusto musical", a pesar de lo cual -asegura- se va "apreciando lo bello", y, por tanto, la obra de Wagner se bastará por sí misma para "sostenerse en nuestra patria"26. Llegados a este punto de crispación, Dietro le Scene propone la "suspensión de hostilidades", una tregua aceptada por la revista de Vidal, que, no obstante, advierte de su intención de defender en lo sucesivo la música de Wagner ${ }^{27}$.

Pendiente la prensa española del ambiente previo, los ensayos y la expectación suscitada en Milán ${ }^{28}$, el 20 de marzo de 1873 se presenta Lohengrin en la Scala ante una concurrencia extraordinaria ${ }^{29}$ y con una espléndida mise en scene. La función se convierte en una "descomunal batalla" ${ }^{30}$ en que las protestas con gritos y silbidos son contestadas por otra sección del público con fragosos aplausos. Tanto El Imparcial como La España Musical ${ }^{31}$ atribuyen el dudoso éxito el día del estreno a la mala interpretación, especialmente de los coros. En las sucesivas representaciones gran parte del público protesta con energía contra los silbidos de los antiwagneristas, que, en una función intercalada de Un ballo in maschera, se organizan gritando consignas en pro de la música italiana y Verdi ${ }^{32}$.

Una crítica aparecida el 1 de abril en El Correo de Teatros, calificando de "soporífero" el dúo entre Ortruda y Telramondo, provoca una nueva polémica con La España Musical. Ésta considera el juicio como propio de un apasionado partidario de la ópera italiana ${ }^{33}$ y observa en su colega una marcadísima preferencia por lo que reputa como música "ligera". Tras siete representaciones, El Correo de Teatros anuncia la retirada de Lohengrin en Milán, asegurando que la última no llega a finalizar ante las protestas, por lo que La España Musical le aconseja utilizar fuentes más fiables que Il Trovatore $^{34}$ y su corresponsal en la capital lombarda ${ }^{35}$.

A lo largo del mes de abril y paralelamente se desarrolla en Madrid una polémica entre Peña y Goñi y B., crítico musical de El Correo Militar, que en su número del día 3 habla de influencia mozartiana en Fausto de Gounod. A un elocuente suelto escrito por Peña, criticando ésta y otras ocurrencias de este "revistero musical" ${ }^{36}$, siguen una primera réplica de El Correo Militar y la contrarréplica del donostiarra ${ }^{37}$. El tono sube cuando $B$. se muestra partidario de ejercer la crítica sin tener preparación técnica, porque,

26 “Wagner en Italia. L'Affondatore a la barra”, en La España Musical, viII/344 (8.02.1873), pp. 1-2.

27 "Wagner en Italia. Al periódico Dietro le Scene", en La España Musical, vIII/346 (22.02.1873), p. 3.

28 "Sección de Espectáculos", en El Imparcial, 28.02.1873.

29 "Noticias extranjeras", en La España Musical, viII/351 (29.03.1873), p. 8.

30 "Sección de Espectáculos", en El Imparcial, 03.04.1873.

31 "Noticias extranjeras", en La España Musical, vIII/353 (12.04.1873), p. 8.

32 "Sección de Espectáculos", en El Imparcial, 03.04.1873.

33 Cuspinera, Clemente: “Wagner en Italia. El Lohengrin en Milán”, en La España Musical, viII/353 (12.04.1873), pp. 2-3.

34 Este "periodicucho, o cosa asî" - dice La España Musical- es "la más insulsa, la más vanidosa, la más fatua, la más necia y la menos veraz de las publicaciones italianas”. "Un periódico veraz (¿?)”, en La España Musical, vIII/339 (04.01.1873), p. 3. 35 La España Musical, viII/354 (19.04.1873), p. 4.

36 “¡Gounod pretendiendo imitar a Mozart en el Faust! ¡Por Dios y por la Virgen Santísima! ¡Nos faltan fuerzas para hacer comentarios!”. [PeÑa Y GoÑI, Antonio]: “Sección de Espectáculos”, en El Imparcial, 05.04.1873.

37 P. [PeÑa y GoÑI, Antonio]: "Sección de Espectáculos”, en El Imparcial, 09.04.1873. 
en su opinión, se aprecia mejor la belleza que siendo un crítico con estudios musicales. Tras recordar una larga lista de teóricos y compositores que han practicado la crítica musical, entre ellos Wagner, Peña se muestra convencido de que "para criticar música, se necesita cuando menos entender algo de ella" ${ }^{38}$ y, retomando el tema de origen, destaca la influencia wagneriana en el primer acto de Fausto como prioritaria y fundamental ${ }^{39}$. El día $15 \mathrm{~B}$. da por cerrada la discusión, no sin antes hacer duros y gratuitos comentarios sobre Wagner y el crítico wagneriano ${ }^{40}$, quien deslegitima el criterio de $B$. y la autoridad en la que basa sus juicios: Marco Scudo ${ }^{41}$. Poco después -y tras subrayar la influencia wagneriana en el monólogo de Felipe II de Don Carlos de Verdi- Peña interpreta que las polémicas surgidas en los estrenos de Lohengrin en Bolonia y Milán son fruto del exagerado amor propio nacional y contribuyen en gran medida al inmenso éxito de Aída en los teatros italianos ${ }^{42}$.

\section{POLÉMICA EN TORNO A JOSÉ CASTRO Y SERRANO Y EL KRAUSISMO (1873)}

Bajo el pseudónimo de Un Caballero Español, antes de concluir 1873 y en un escrito dedicado a Peña y Goñi, José Castro y Serrano explica la teoría wagneriana, aboga por la subvención oficial para representar los dramas de Wagner en Madrid y subraya la necesidad de que los músicos jóvenes estudien la obra del compositor alemán ${ }^{43}$. El artículo de Castro y Serrano, muy leído y comentado en las tertulias del Ateneo de Madrid -organismo que en palabras de Peña y Goñi es "sin duda alguna el más importante tratándose del porvenir de Wagner en España" ${ }^{44}$ - causa una impresión profundísima y da lugar a calurosos debates. El Arte, semanario que entonces está publicando un estudio sobre la ópera española del antiwagneriano José Parada y Barreto, prologado por el también antiwagneriano Hilarión Eslava ${ }^{45}$, propone el predominio de la melodía y la simplicidad en la orquestación, en consonancia -comenta un suelto anónimo- con "algunos jóvenes maestros italianos que tratan de seguir en sus obras un camino opuesto al que siguen los wagneristas, o sea, los krausistas de la música moderna" ${ }^{46}$. El Trovador contesta en el artículo "Una protesta a favor del espíritu musical de nuestro tiempo", calificando al autor del suelto como retrógrado, tradicionalista y apegado a lo antiguo. El Arte replica en un artículo de idéntico título retando a El Trovador y a Un Caballero Español a que "mantenga su teoría u opinión wagnerista tan pro-

38 P. [Peña y GoÑI, Antonio]: “Sección de Espectáculos”, en El Imparcial, 13.04.1873.

39 PeÑa y GoÑI, Antonio: "Sección Musical. Al Sr. B.”, en El Imparcial, 15.04.1873.

40 PeÑa y GoÑI, Antonio: “Sección Musical. Al Sr. B. II”, en El Imparcial, 16.04.1873.

41 Peña y GoÑI, Antonio: "Crónica Musical”, en El Imparcial, 22.04.1873.

42 PeÑa y GoÑI, Antonio: “Giuseppe Verdi”, en La Ilustración Española y Americana, XVII/19 (16.05.1873), p. 310.

43 Un Caballero Español [CAStro Y Serrano, José]: "Viaje alrededor de la Exposición Universal de Viena. XIII. Wagner", en La Ilustración Española y Americana, XVII/46 (08.12.1873), pp. 742-744.

44 Peña y GoÑI, Antonio: "Preludios del Porvenir", en La Ilustración Española y Americana, xviII/1 (08.01.1874), p. 11.

45 Parada y Barreto, José: La ópera nacional. Estudio crítico-analítico de la cuestión de la ópera española con instrucciones, observaciones y consejos útiles y provechosos a los poetas y a los jóvenes compositores de música que se dediquen en España al cultivo del drama lírico, por D. José Parada y Barreto, con un prólogo del Excmo. Sr. D. Hilarión Eslava. Madrid, Imp. de El Arte, 1873. En prensa en El Arte, i/7 (15.11.1873, pp. 5-6) y ss.

46 "Noticias extranjeras", en El Arte, I/13 (27.12.1873), p. 7. 
nunciada e intransigente, seguros de que la hemos de echar por tierra cual si fuera un castillo de naipes" ${ }^{47}$. No hemos localizado hasta la fecha ninguna contrarréplica de El Trovador o de Castro y Serrano, aunque Peña y Goñi escribe una serie, dedicada a Un Caballero Español, compuesta por los artículos "Preludios del Porvenir"48, "Ricardo Wagner"49 y "La Melodía Infinita"50. Esta polémica pone de manifiesto que el wagnerismo madrileño tiene en este momento una connotación que, yendo más allá del hecho estético, lo relaciona con la ideología progresista, como hemos subrayado en otro lugar ${ }^{51}$.

\section{POLÉMICA ENTRE LA “SOCIEDAD WAGNER” DE BARCELONA Y JOSÉ PIQUÉ (1874)}

Por iniciativa de uno de los redactores de La España Musical, N. Pons, y ante el entusiasmo despertado tras la interpretación de dos partituras sobre Lohengrin y Tannhäuser en la serie de conciertos de primavera realizada por la Sociedad de Cuartetos de Barcelona en el Teatro Español en mayo de $1873^{52}$, se crea la Sociedad Wagner. En este caso, no se trata de financiar el Festival de Bayreuth, sino de estudiar y dar a conocer las obras del maestro alemán ${ }^{53}$. A principios de verano, la naciente Sociedad se pone en contacto epistolar con el compositor, comunicándole su fundación, ofreciéndole la presidencia honorífica y trasladándole que su primer objetivo es la promoción de su trabajo, preguntándole en este sentido sobre el programa para un concierto ${ }^{54}$. A través de Cósima, Wagner contesta ${ }^{55}$ a Andrés Vidal y Roger aceptando la presidencia, aconsejando sobre las partituras que con preferencia deben ejecutarse en los conciertos y prometiendo dedicar una nueva composición a la Sociedad para ser estrenada el día de su inauguración ${ }^{56}$, aunque, hasta el momento, no tenemos constancia de la realización de esta promesa.

Hay que esperar a la primavera de 1874 para que se instituya oficialmente la Sociedad Wagner, cuyo propósito se condensa en la frase "todo por y para el arte". Para su constitución se aprovecha el estreno en el Liceo de L'Ultimo Abbenzerraggio, partitura de Pedrell presentada el 14 de abril en la que aún no puede hablarse de wagnerismo como sistema ${ }^{57}$, aunque la prensa destaca la influencia wagneriana en el cuarteto

47 "Una protesta a favor del espíritu musical de nuestro tiempo", en El Arte, i/15 (11.01.1874), p. 4.

48 Peña y GoÑI, Antonio: "Preludios del Porvenir. A un Caballero Español", en La Ilustración Española y Americana, XVIII/1 (08.01.1874), pp. 11 y 14.

49 PeÑa y GoÑI, Antonio: "Ricardo Wagner. A un Caballero Español", en La Ilustración Española y Americana, XVIII/2 (15.01.1874), pp. 19, 20 y 22.

50 PeÑa y GoÑI, Antonio: "La Melodía infinita. A un Caballero Español”, en La Ilustración Española y Americana, XVIII/7 (22.02.1874), pp. 107-110.

51 SuÁrez García, José Ignacio: "Liberalismo y wagnerismo en Madrid en el Sexenio Revolucionario", en Alonso, Celsa, Gutiérrez, Carmen Julia y SuÁrez-Pajares, Javier (eds.): Delantera de paraíso. Estudios en homenaje a Luis G. Iberni. Madrid, ICCMU, 2008, pp. 353-368.

52 Estos conciertos dan pie, una vez más, a que La España Musical acuse a El Correo de Teatros de dejarse llevar por los periódicos italianos "que anatematizan al clásico Wagner". La España Musical, vIII/361 (07.06.1873), p. 4.

53 La España Musical, viII/360 (31.05.1873), p. 8.

54 Wagner, Cosima (Gregor-Dellin, Martin y Mack, Dietrich eds.): Diaries. Vol. I “1869-1877”. Nueva York y Londres, Harcourt Brace Jovanovich, 1980, p. 654.

55 WAGNer, Cosima; op. cit., p. 655.

56 La España Musical, viı/367, (19.07.1873), p. 4.

57 CoRTès, Francesc: “Ópera española: las obras de Felipe Pedrell”, en Cuadernos de Música Iberoamericana, 1 (1996), p. 191. 
del cuarto acto y en el papel preponderante de la orquesta ${ }^{58}$. La Sociedad organiza su concierto inaugural con una selección de obras escogidas por Wagner ${ }^{59}$ y en la cuarta representación, el 23 de abril ${ }^{60}$, regala a Pedrell una escribanía de plata con el retrato del compositor alemán ${ }^{61}$.

En este contexto se abre una nueva polémica wagneriana que, surgiendo en Barcelona, se trasladará posteriormente a Madrid. Su detonante es la exclusión de obras de Wagner y compositores modernos en el primero de los conciertos de cuaresma organizados por el Ateneo de Barcelona, lo que provoca las protestas de Francisco de Paula Carbonell en dos sueltos publicados en La Imprenta ${ }^{62}$. Ocultando su nombre, un miembro de la comisión encargada de configurar los programas del Ateneo, José Piqué y Cerveró, desacredita a la crítica musical de tendencia wagneriana y, con ironía, asegura que en lo sucesivo excluirá las composiciones españolas e italianas para, por el contrario,

"a fin de que el nombre del autor tenga por sí solo un aspecto de peregrina novedad y sirva de recomendación a la entusiasta juventud para que aplauda a rabiar, daremos la preferencia a las de aquellos que acaban en gnof, gnits, gner, etc., etc. ¡Ah! ... esta última sílaba ¡qué influencia tan colosal posee! Supongo comprenderá V. que corresponde al reformador de la música dramática, al divino Wagner"63.

Tras este escrito, contestado por Carbonell sin mayores consecuencias ${ }^{64}$, interviene el presidente de la Sociedad Wagner en Barcelona, José Pujol Fernández, quien se muestra dispuesto a entablar polémica siempre y cuando el miembro del Ateneo firme sus escritos ${ }^{65}$.

Estampando su firma, Piqué y Cerveró pregunta por qué la Sociedad no ha escogido el de Eslava, Arrieta o Barbieri para darle nombre, máxime teniendo en cuenta que, a diferencia de otros reconocidos compositores, Wagner es un autor de mérito contradictorio, amparado por un "príncipe apasionado". Además, está dispuesto a probar que su reforma dramática es antimusical y un retroceso "que el sentimiento de lo bello y la naturaleza del arte mancomunadamente rechazan"66.

José Pujol explica, precisamente, que la elección de Wagner se debe a su faceta reformadora, sin menosprecio de los maestros españoles citados, recordando, al mismo tiempo, que la que preside no es una sociedad exclusivamente wagneriana, sino que, como recoge su reglamento ${ }^{67}$, pretende dar a conocer

58 “Juicio de la prensa. L'Ultimo Abenzerraggio. Drama en cuatro actos de don F. Fors de Casamayor, música del maestro Pedrell”, en La España Musical, Ix/406, (25.04.1874), p. 7.

59 Pedrell, Felipe: Jornadas de Arte (1841-1891). París, Librería Paul Ollendorff, [1911], pp. 37-38.

60 La España Musical, IX/405, (18.04.1874), p. 8.

61 “Juicio de la prensa. L'Ultimo Abenzerraggio. Drama en cuatro actos, de don F. Fors de Casamayor. Música del maestro Felipe Pedrell", en La España Musical, IX/406 (25.04.1874), pp. 4, 7 y 8. La prensa de Madrid también comenta el regalo de la Sociedad Wagner a Pedrell [El Arte, II/32 (10.05.1874), p. 3].

62 La Imprenta, 24.03.1874 y 01.04.1874 (edición de tarde).

63 N. N. [Piqué y Cerveró, José]: “Remitido”, en La España Musical, IX/404 (11.04.1874), p. 3.

64 Carbonell, Francisco de Paula: "Remitidos", en La España Musical, Ix/405 (18.04.1874), p. 4.

65 Pujol Fernández, José: “Remitidos”, en La España Musical, ix/405 (18.04.1874), p. 4.

66 Piqué y Cerveró, José: “Remitido”, en La España Musical, IX/407 (02.05.1874), pp. 7-8.

67 "Wagner. Sociedad Artístico-Musical. Reglamento”, en La España Musical, IX/412 (06.06.1874), pp. 2-4. 
cualquier composición nacional o extranjera de reconocido mérito. Asimismo, cree que considerar la reforma wagneriana como un retroceso es un error, ya que "la forma en expresar el sentimiento de lo bello es infinita" ${ }^{68}$.

Piqué, que no reconoce a Wagner como "compositor en el alto significado de la palabra", se centra en la oposición ópera italiana / drama wagneriano, cuya reforma encuentra equivocada, porque la forma en expresar el sentimiento de lo bello no es infinita. Infinito -dice- "es la idea, el pensamiento o concepto" porque la forma "ha de ser adecuada al fin que el artista se ha propuesto; por consiguiente, tiene sus límites marcados por el buen sentido". Siendo el arte "ideal" por excelencia, la música debe imitar a la naturaleza, es decir, a los cantos y danzas populares. Esta imitación es, precisamente, lo que diferencia a las bellas artes de las ciencias naturales, cuyo planteamiento (análisis y cálculo) parece seguir la música de Wagner. Por consiguiente -concluye- "imite Wagner a la naturaleza haciendo cantar melódica y sentimentalmente a las voces [y] no las prostituya" ${ }^{\circ}$.

Amparándose en que su interlocutor no considera a Wagner como compositor "en el alto significado de la palabra", al mismo tiempo que no define cuál es el límite de la forma para expresar lo bello, Pujol elude el debate de contraposición de escuelas, centrando la discusión en la valoración intrínseca de la producción wagneriana. Así, propone a su contrincante la elección de la partitura de Wagner que desee y señale sus defectos, convencido de su refutación. Si Piqué no aceptara el reto, o resultara vencido -dice Pujol- "proclamaré muy alto que mi opositor ha criticado a Wagner [...] sin conocimiento de causa"70.

Piqué acepta el desafío exigiendo dos condiciones: en primer lugar propone como jueces a un mínimo de nueve compositores de tres obras dramáticas aplaudidas de cualquier país salvo Alemania y, en segundo lugar, que la Sociedad Wagner corra con todos los gastos que se ocasionen ${ }^{71}$.

\section{POLÉMICA ENTRE FRANCISCO A. BARBIERI Y ANTONIO PEÑA Y GOÑI (1874)}

Al parecer las condiciones exigidas no son aceptadas, puesto que La España Musical no recoge más noticias sobre la polémica en Barcelona. Sin embargo, contestando a un remitido impreso en un suplemento de El Correo de Teatros en que Piqué realiza una calurosa defensa de los músicos españoles, Barbieri escribe "Cartas musicales. Primera sobre la música de Ricardo Wagner"72, dedicada a Piqué. Pretendiendo mediar entre los polemistas, Barbieri explica la música como un arte necesariamente revolucionario en que innovaciones desechadas tiempo atrás, se convierten posteriormente en principios admitidos, estando solamente en manos del público decidir cuáles permanecen. Otro tanto ocurre con el mérito de cualquier composición y, en este sentido, sólo el juicio del público dirimirá el valor de la producción wag-

68 Pujol Fernández, José: "Remitido", en La España Musical, IX/408 (09.05.1874), pp. 6-7.

69 Piqué y Cerveró, José: "Remitidos", en La España Musical, Ix/411 (30.05.1874), pp. 4-5.

70 Pujol Fernández, José: "Remitido", en La España Musical, Ix/413 (13.06.1874), p. 8.

71 PiQué y Cerveró, José: "Remitido", en La España Musical, IX/415 (27.06.1874), pp. 4 y 7.

72 [Asenjo] Barbieri, Francisco: "Cartas musicales. Primera sobre la música de Wagner", en Revista Europea, i/25 (16.08.1874), pp. 216-220. 
neriana. Antes de opinar sobre la obra de Wagner -y pretendiendo aparecer como juez imparcial- Barbieri se preocupa en desmentir el antiwagnerismo a él adjudicado por Peña y Goñi haciendo uso de apreciaciones expresadas privadamente ${ }^{73}$, recordando, al mismo tiempo, que fue él quien presentó en Madrid la Marcha de Tannhäuser ${ }^{74}$. Tras criticar la oscuridad del pensamiento de Wagner, Barbieri destaca algunas contradicciones existentes entre su teoría y praxis, llamando la atención sobre la periodicidad del fraseo de buena parte del repertorio wagneriano, opuesto al concepto de melodía infinita. En su opinión, Wagner posee tres espíritus diferentes e inarmónicos para la poesía, la crítica y la música: en sus obras literarias encuentra un afán de singularizarse a toda costa y de buscar la originalidad; en su obra crítica, falta de fundamentos estéticos claros y un "batiburrillo filosófico que no hay quién lo entienda"; como compositor no tiene sistema de composición definido ni "estilo propio individual", porque sus obras recuerdan en ocasiones a Schumann, Liszt, Spohr y, en otras, a Mendelssohn, Weber y Meyerbeer. Aunque reconoce el mérito de las partituras en que Wagner sigue las tendencias generales del Romanticismo, censura aquéllas en que se "complace en dar tortura al mejor período musical, destrozándolo violentamente y de un modo extravagante". Considerando el canto popular como "la expresión más bella del arte natural" y a la melodía como "el alma, el sine qua non del arte de la música", Barbieri censura -como su mayor defecto-el uso "malísimo" que hace Wagner de la voz, "el primero y principal elemento del drama lírico". Por tanto, encuentra en la melodía wagneriana su mayor contradicción, porque en contra de su pretendido realismo, no se explica cómo Wagner "hace cantar a sus personajes de un modo contrario a las leyes de la naturaleza y del arte". No hay en el mundo -dice Barbieri- "quien espontáneamente hable o cante de manera tan desentonada [...], saltando de un registro a otro de la voz, y usando frecuentemente de los puntos extremos, de los intervalos disonantes y de las modulaciones violentas”. Aún así, admite que Wagner no es un compositor vulgar, siendo capaz de conmover y despertar admiración en ocasiones, aunque no se atreve a pronosticar qué lugar le corresponderá en la música. Como mediador en la polémica, aconseja moderación a las dos partes, porque cree a ambas equivocadas: los wagneristas al prescindir de la tradición y los antiwagneristas al obviar las transformaciones experimentadas en la música dramática.

Publicado el 16 de agosto en Revista Europea, el escrito de Barbieri es ampliamente comentado en la prensa musical y diaria. Isidoro Fernández Flórez anuncia al día siguiente una próxima réplica de su compañero en El Imparcial, Peña y Goñi ${ }^{75}$, mientras La España Musical, que también reproduce el artículo de Barbieri ${ }^{76}$, comunica su intención de incluir próximamente entre sus páginas la respuesta de Peña, con el propósito de que sus lectores tengan conocimiento de "cuanto se publica en España acerca de la tan debatida cuestión de Wagner y su música"77.

73 Barbieri parece referirse a un monográfico en que Peña asegura que a él "Wagner le ataca a los nervios. La batalla de Waterloo, las cataratas del Niágara, [...] la insurrección de Cartagena, todo eso es nada al lado de las disonancias de Wagner, comentadas por Barbieri”. PeÑa y GoÑI, Antonio: "Bocetos musicales. Barbieri”, en El Imparcial, 20.04.1874.

74 Barbieri dirige esta partitura en los conciertos organizados en 1864 por la Sociedad Artístico-musical de Socorros mutuos. Hemos ponderado su presunto antiwagnerismo en SuÁrez Garcia, José Ignacio, "La recepción de la obra de Richard Wagner en Madrid entre 1861 y 1876”..., op. cit., pp. 73-74.

75 Un Lunático [FERnÁndez FlóREZ, Isidoro]: “Madrid”, en Los Lunes de El Imparcial, 17.08.1874.

76 La España Musical, IX/424 (29.08.1874), pp. 3, 4 у 7.

77 La España Musical, Ix/424 (29.08.1874), p. 8. 
Contestando a las intencionadas alusiones de Barbieri, Peña y Goñi escribe "Teratología Musical. iißBarbieri wagnerista!!!”78, artículo aparecido en primera página de El Imparcial el 18 de agosto, una prueba de la importancia de esta querella como tema de actualidad. En tono jocoso, Peña se asombra de la pretendida imparcialidad de Barbieri, porque -ya en tono más serio- le recuerda que su condición de antiwagnerista no se debe a opiniones expresadas privadamente, sino a escritos como su biografía sobre Eximeno $^{79}$, en que Barbieri asegura encontrarse en una época en "que los delirios de Wagner y su escuela tienden a PERVERTIR POR COMPLETO la música, convirtiéndola de encantador lenguaje del alma en una especie de cálculo matemático". Tras recordarle, asimismo, la autoría de una parodia sobre la música del porvenir, incluida en su zarzuela Sueños de Oro, Peña precisa que Wagner no es el creador de esta expresión y que, precisamente, el compositor alemán se ha defendido de esa falsa imputación en sus escritos, retando a Barbieri a que indique dónde Wagner se declara inventor de una música del porvenir.

Convirtiéndose la polémica en noticia de rabiosa actualidad ${ }^{80}$, Barbieri contesta en "Cartas Musicales. Segunda a D. Antonio Peña y Goñi”" ${ }^{11}$, un escrito fechado el 19 de agosto y dominado por cierto tono paternalista, en el que el compositor de zarzuela achaca los impetuosos juicios de Peña a su vehemencia juvenil. Barbieri considera que en su primer artículo ha tratado la cuestión desde una posición imparcial, sin ser partidario exagerado de Wagner (wagnerista) ni absolutamente contrario a él (antiwagnerista), en un momento caracterizado por las "semibatallas" producidas en las sesiones de la Sociedad de Conciertos. De ahí que para probar su imparcialidad -y con la intención de mediar entre los querellantes- se haya visto obligado a recordar que para introducir la obra de Wagner en Madrid, tuvo que tomarse la molestia de comprar, traducir, ensayar y estrenar la Marcha de Tannhäuser, acusando a Peña de haber ocultado intencionadamente sus opiniones favorables acerca del compositor alemán. Sobre la cita de la biografía de Eximeno, Barbieri aclara que no condena las obras "razonables" de Wagner, sino tan sólo sus "delirios", aberraciones y extravagancias "que son las que realmente tienden a pervertir la música". Por último, responde al reto planteado por Peña sobre la autoría de la expresión música del porvenir siguiendo la Biographie des musiciens de Fétis:

"En el año de 1850 publicó Ricardo Wagner en Leipzig un libro intitulado La Obra de Arte del Porvenir. En este libro, muy conocido, publicó las bases de su pretendido nuevo sistema de composición musical, bases que luego desarrolló más por extenso en otros libros, que no es del caso citar ahora. Desde entonces todas las gentes dieron en señalar las obras de Wagner con el nombre de música del porvenir, y con tal nombre fue conocida en toda Alemania y aun fuera de allí, sin que a Wagner durante unos diez años se le ocurriera protestar contra tal denominación. Pero como entre

78 PeÑa y GoÑI, Antonio: “Teratología Musical. ¡ißBarbieri Wagnerista!!!”, en El Imparcial, 18.08.1874. También en La España Musical, IX/425 (05.09.1874), pp. 2-4.

79 Prólogo de Barbieri a la novela Don Lazarillo Vizcardi (1872). Puede consultarse en Casares Rodicio, Emilio: Francisco Asenjo Barbieri. Vol. II, "Escritos". Madrid, ICCMU, 1994, pp. 300-319.

80 El Arte, $\mathrm{II} / 47$ (25.08.1874), p. 3.

81 [Asenjo] Barbieri, Francisco: "Cartas musicales. Segunda a D. Antonio Peña y Goñi”, en Revista Europea, i/26 (23.08.1874), pp. 260-263. También en La España Musical, IX/426 (12.09.1874), pp. 2,7 y 8. 
los alemanes también hay gente zumbona y maleante, no faltó quien se aprovechara de los malos éxitos de algunas composiciones de Wagner, para decir que su música del porvenir era en realidad música del pasado. Esto tal vez contribuyó a que, en efecto, Wagner luego, cuando fue a poner en escena su desgraciado Tannhäuser en París, protestara enérgicamente contra semejante denominación, pero no victoriosamente, como tú dices, porque ni pudo arrancar de las bibliotecas su libro, ni de la memoria de las gentes el recuerdo de que él mismo había titulado con tal nombre su propia obra elemental; y para el caso concreto que tratamos, tanto vale decir obra de arte del porvenir como música del porvenir, puesto que de lo que se trata es de música en ambos extremos. La cuestión, o mejor dicho, el asunto es aquí el porvenir, QUE WAGNER FUE EL PRIMERO EN SACAR A PLAZA, sin que su tardía protesta o notoria inconsecuencia, como otras muchas suyas, bastara a borrar el título consabido. Hoy mismo en todas partes se llama música del porvenir a la de Ricardo Wagner, y en el mismo Munich, donde él habita, se le atribuye vulgarmente el dicho «Die Zukunft wird meine Musik annehmen», que traducido libremente significa: «Mi música será aplaudida en el porvenir».

Ya estás contestado, querido Peña"82.

Aclaramos brevemente las palabras de Barbieri. Música del futuro, un escrito incluido en Quatre poèmes d'Opéras traduits en prose française... ${ }^{83}$ (París, 1860) se publica independientemente en alemán en 1861 bajo el título de Zukunftsmusik ${ }^{84}$. En él, Wagner desmiente, precisamente, el tópico inventado en Alemania en torno a la expresión "música del porvenir", atribuida por la prensa española al propio Wagner en la década de $1860^{85}$. Como señala Barbieri, el propio título de su escrito anterior, La Obra de Arte del Futuro $^{86}$, reunió los requisitos para sumir a sus contemporáneos en la confusión o en la burla, transformado enseguida y peyorativamente en Zukunftsmusik por el crítico de Colonia Ludwig Bischoff. El término, arrastrado desde 1847 para referirse a Chopin, Liszt y Berlioz ${ }^{87}$, y anotado en 1854 por el crítico vienés L. A. Zellner y el compositor Louis Spohr, no se difundirá por Europa hasta 1859, utilizado por Bischoff en el primer número de la Niederrheinische Musiskzeitung ${ }^{88}$.

El mismo día en que Revista Europea publica el artículo de Barbieri, el 23 de agosto, Peña contesta en la primera parte de "Wagner y la música del porvenir", sacada nuevamente en primera página de $E l$ Imparcial el 28, y cuyo inicio, denota cierto resquemor ante el tono paternalista y ex cathedra empleados por Barbieri. Para Peña, Barbieri wagnerista sigue siendo algo contra natura, una monstruosidad, en defi-

82 [Asenjo] Barbieri, Francisco: "Cartas musicales. Segunda a D. Antonio Peña y Goñi”, en Revista Europea, i/26 (23.08.1874), pp. 262-63.

83 WAGNER, Richard: Quatre poèmes d'Opéras traduits en prose française précèdes d'une lettre sur la Musique; par Richard Wagner. París, Librairie Nouvelle, 1860.

84 WAGNER, Richard: Zukunftsmusik. Leipzig, J. J. Weber, 1861.

85 Cuenca, Vicente: "Concierto en los Jardines de Apolo, bajo la dirección del Señor Barbieri", en El Artista, I/9 (07.08.1866), p. 5 .

86 WaGner, Richard: Das Kunstwerk der Zukunft. Leipzig, Otto Wigand, 1850. 734.

87 Wagner, Richard (Gregor-Dellin, Martin ed. y Mayo, Ángel F. trad.): Mi vida. Madrid, Turner, 1989, pp. 426, 716 y

88 BAuER, Hans-Joachim (BAs, Belén trad.): Guía de Wagner. Madrid, Alianza, 1996, Vol. II, p. 810. 
nitiva, un caso teratológico, porque su única argumentación para defenderse del epíteto de antiwagneriano descansa en el hecho de haber sido el introductor de la Marcha de Tannhäuser en Madrid. Con ello, Barbieri únicamente había cumplido con su deber como director de una sociedad de conciertos y Peña llega a preguntarse si, renunciando a su gusto personal, lo había hecho solamente para complacer al público. Asimismo, destaca que esta partitura no da una idea general acerca de la música de Wagner y que si ésta gusta a Barbieri es porque, como le ha oído decir en numerosas ocasiones, los procedimientos en ella utilizados no son los predicados por su autor. Por último, apelando a su autoridad musical y su influencia sobre la opinión pública -como compositor popular por excelencia- le invita a que dé una opinión detenida y formal sobre la música de Wagner y no se limite, como hasta entonces, a señalar que tiene obras malas y buenas y que el tiempo decidirá sobre su valor ${ }^{89}$.

La segunda parte de "Wagner y la música del porvenir", fechada el 24 de agosto y publicada nuevamente en primera página de El Imparcial el 29, se centra en la autoría de la expresión música del porvenir. Basándose en el testimonio de Wagner, Peña demuestra que el concepto de obra de arte total (Gesamtkunstwerk), enunciado en La Obra de Arte del Futuro y desarrollado en Ópera y Drama ${ }^{90}$, no es exclusivamente musical, porque plantea la reunión global de las artes. Éste es el argumento utilizado por el compositor alemán para demostrar que su obra de arte del futuro no equivale a la locución música del porvenir, como expresa claramente un fragmento de Música del futuro traducido por Peña y tomado de su primera versión francesa ${ }^{91}$ :

"Trataba yo de esta manera de representarme LA OBRA DEL ARTE que debe abarcar todas las artes particulares para hacerlas cooperar a la realización superior de su objeto; llegué por este camino a la concepción reflejada del ideal que oscuramente se había formado en mí, vaga imagen a la que el artista aspiraba. La posición subordinada del teatro en nuestra vida pública, situación cuyos vicios había yo tan perfectamente reconocido, no me permitía creer que este ideal pudiese llegar en nuestros días a una completa realización; lo designé, pues, bajo el nombre de Obra de Arte del porvenir, título que di a un extenso escrito en el que exponía con más detalles las ideas que acabo de indicar. A este título debemos (sea dicho de paso) ese espectro tan bien inventado, de una «música del porvenir». Este espectro ha llegado a ser tan popular, que se le ha visto correr como un aparecido hasta en escritos franceses. Claramente podréis comprender ahora la equivocación sobre que descansa ese espectro y el objeto con que ha sido ideado".

Una nueva cita insiste en el error de identificar los conceptos de obra de arte del futuro y música del futuro ya que, lejos de ser una reforma exclusivamente musical, Wagner pretende una íntima unión entre música y texto, y sus poemas -basados en lo mitológico y legendario- prescinden de todas las "concesio-

89 Peña y GoÑI, Antonio: "Wagner y la música del porvenir", en El Imparcial, 28.08.1874. También en La España Musical, IX/427 (19.09.1874), pp. 3-4.

90 Wagner, Richard: Oper und Drama. Leipzig, J. J. Weber, 1852.

91 WAGner, Richard: Quatre poèmes d'Opéras traduits en prose française..., op. cit., p. 20. 
nes banales de un libreto de ópera". Por tanto, mi innovación -dice Wagner en traducción de Peña- "de ninguna manera consiste en no sé qué revolución arbitraria, TODA MUSICAL, de la que se ha tenido a bien imputarme la idea y tendencia con esta hermosa frase, MúSICA DEL PORVENIR". Peña pone fin al artículo con la esperanza de que sea como sea la contestación de Barbieri se mantenga su amistad por encima de todo, pero de las palabras de cierre del artículo ${ }^{92}$, así como por documentos posteriores, parece desprenderse que las relaciones entre ambos se enfriaron por breve espacio de tiempo. Su amistad volvió al tono de cordialidad habitual al escribir Peña "El piano de Barbieri" ${ }^{93}$, contestado por el compositor en una carta en que se muestra sinceramente agradecido a Peña y sorprendido después de recordarle "lo que me hiciste padecer con tus disonancias del porvenir" ${ }^{\prime 94}$.

\section{POLÉMICA ENTRE FRANCISCO A. BARBIERI Y RUPERTO CHAPÍ (1878)}

El 25 de enero de 1878 el Ayuntamiento de Madrid organiza en el Teatro Real una función de gala para festejar el enlace de Alfonso XII con María de las Mercedes de Orleáns. En la velada se interpretan la Cantata de Arrieta compuesta para el enlace real y los dos primeros actos de Roger de Flor de Chapí, partitura escrita en su estancia como pensionado de la Academia en Roma y de clara influencia wagneriana en su instrumentación ${ }^{95}$. Esta influencia -también presente en su ópera anterior, La hija de Jefté $e^{96}$ es destacada por Peña y Goñi ${ }^{97}$ en su estreno absoluto en el teatro Real el 11 de febrero, y se debe a que, siguiendo la tendencia general de los alumnos del Conservatorio de Roma, Chapí "ha estudiado detenidamente a Meyerbeer y a Wagner" ${ }^{98}$, cuyo estilo se reconoce en mucha parte de la instrumentación"99.

En "Carta a un joven compositor de música”, Barbieri critica la exuberancia, la excesiva acumulación de combinaciones rítmicas y de modulaciones intrincadas, la falta de claridad, la simultaneidad de ritmos, el tratamiento antioperístico de las voces y la compleja orquestación de Chapí. En el artículo, extracto de una carta anterior, Barbieri recomienda al joven compositor que se aparte de la influencia wagneriana y siga la tendencia de las óperas de Mozart, Rossini, Donizetti, Verdi, Meyerbeer y Gounod, porque, dice:

"nutrido de tan excelente savia, debe Vd. aspirar a que las obras con que inaugure su carrera pública de compositor sean ante todo claras y expresivas para que sean generalmente aplaudidas y

92 PeÑa y GoÑI, Antonio: “Crítica Musical. Wagner y la música del porvenir II”, en El Imparcial, 29.08.1874. También en La España Musical, IX/428 (26.09.1874), pp. 1-2.

93 PeÑa y GoÑI, Antonio: "El piano de Barbieri”, en La Crítica, I/3 (29.10.1874), pp. 1-3. p. 336.

94 Citado en Casares Rodicio, Emilio: Francisco Asenjo Barbieri. Vol. I, "El hombre y el creador". Madrid, ICCMU, 1994,

95 "Sección de espectáculos", en El Imparcial, 26.01.1876.

96 IberNi, Luis G.: Ruperto Chapí. Madrid, ICCMU, 1995, p. 73.

97 Peña y GoÑI, Antonio: “Teatro Real”, en El Tiempo, 21.02.1878.

98 En 1875 Chapí estudia en Roma las partituras de Rienzi, El Holandés errante, Tannhäuser y Lohengrin. GRACIA IBERNI, Luis, op. cit., pp. 68-69.

99 “Sección de espectáculos”, en El Imparcial, 12.02.1876. 
le den reputación; porque ésta no es fácil de adquirir, al principio, y menos aún cuando uno se echa por el camino de eso que $\mathrm{Vd}$., muy justamente llama la pícara novedad.

No crea Vd. por esto que yo condeno en absoluto la música de Wagner y sus afines; tal vez sucederá con ella lo que sucedió con las reformas que Góngora introdujo en nuestra poesía; que, andando el tiempo, se deseche lo extravagante y bastardo, quedando como bueno en el arte lo bello y legítimo de que sin duda hay rasgos en sus óperas del reformador alemán: lo que sí digo, y es una gran verdad, es que hoy la música de Wagner se halla todavía en tela de juicio, y que por esto un joven compositor como $\mathrm{Vd}$. no debe tomarla por modelo para sus primeras obras, sino inspirarse en aquélla que ha sancionado con sus aplausos la Europa entera.

Luego que $\mathrm{Vd}$. haya adquirido reputación de compositor, y haya sido aplaudido generalmente, su mismo genio le hará formarse un estilo propio, o más bien, el público se encargará de indicar a Vd. con sus aplausos el camino que debe seguir. Hasta que esto suceda, creo que no debe usted meterse en honduras, ni empeñarse en ser satélite de otro, que aún no han definido bien los sabios si es un astro verdadero o una estrella errante" ${ }^{100}$.

Chapí responde en carta fechada el 22 de febrero, publicada en El Imparcial bajo el título de "Contestación del joven compositor". El maestro de Villena lamenta que el escrito de Barbieri se publique sin fecha, sesgado y con numerosos cortes que suprimen los párrafos más halagüeños hacia su ópera, concluyendo su artículo con el dictamen emitido por el Jurado encargado de examinar sus trabajos como pensionado de segundo año en Roma. El dictamen, acordado por Barbieri y el resto del jurado por unanimidad, destaca el "mérito realmente extraordinario"101 de los trabajos de Chapí y, por tanto, se contradice, en gran medida, con el recortado escrito de Barbieri publicado en El Imparcial.

La polémica evidencia, por una parte, las deterioradas relaciones personales entre Barbieri y Arrieta - maestro y mentor de Chapí- manifestadas en la concesión del primer pensionado de mérito de la Academia, en la que Barbieri opta decisivamente por Bretón y Arrieta por Chapí, pero también que "Barbieri intuía a través del lenguaje de Chapí la entrada de todo el modernismo europeo desde Meyerbeer hasta Wagner y por ello la integración en España de nuevas estéticas con las que no estaba de acuerdo" 102 .

100 [Asenjo] Barbieri, Francisco: "Carta a un joven compositor de Música”, en Los lunes de El Imparcial, 18.02.1878.

101 Chapí, Ruperto: “Contestación del joven compositor. Al Sr. D. Francisco Asenjo Barbieri”, en Los lunes de El Imparcial, 25.02.1878.

102 Casares Rodicio, Emilio: op. cit., vol. I, p. 362. 


\section{POLÉMICA ENTRE JOAQUÍN MARSILLACH Y ANTONIO FARGAS (1878-79)}

En mayo de 1878 aparece en Barcelona Ricardo Wagner. Ensayo biográfico crítico de Joaquín Marsillach ${ }^{103}$, publicado más tarde en Milán traducido al italiano ${ }^{104}$. Aunque existe un monográfico anterior sobre Rienzi ${ }^{105}$, se le considera como el primer libro de autor español sobre Wagner y como tal, tiene una amplia repercusión en la prensa, que anuncia su venta ${ }^{106}$, realiza recensiones críticas ${ }^{107}$ y publica los capítulos primero ${ }^{108}$ y quinto ${ }^{109}$. Pensado para la prensa periódica, el Ensayo de Marsillach presenta un lenguaje sencillo que huye de los tecnicismos musicales, lo que suscita las simpatías del redactor de las Bayreuther Blätter, Hans von Wolzogen. Su objetivo principal es la contraposición de las propuestas wagneriana e italiana, sobre todo en lo que se refiere a las relaciones texto-música. Marsillach, que sigue preferentemente a Edouard Schuré110, censura los libretti de ópera italiana e insiste en que Wagner elimina de sus dramas las concesiones al espectador en busca del realismo y la verosimilitud dramática.

Precede al ensayo de Marsillach un prólogo ${ }^{111}$ epistolar de José de Letamendi que, redactado en Madrid y recogido en sus obras completas ${ }^{112}$, reflexiona sobre la idea de obra de arte total, subrayando que en el drama wagneriano intervienen pintura, escultura, tramoya, mímica, texto y música, formando un todo. En la expresión, Letamendi distingue la idea pura, el tono y el gesto, concluyendo que "distintas ideas exigen tono y gesto distintos"; de esta forma -continúa- "toda repetición [...] debe quedar, en consecuencia, proscrita, como estéticamente intolerable" y, por tanto, la música en el drama debe ser "una serie infinitesimalmente variada de formas y matices; el ideal, en fin, de la recitación espontánea". Asimismo destaca el papel de la orquesta, que no debe ser un mero acompañante, sino un "alter ego del canto" que sirva de refuerzo psicológico de la expresión y vacíe "la conciencia del personaje ante el público" para decir "lo que el personaje calla". El prólogo de Letamendi, traducido al alemán en las Bayreuther Blätter ${ }^{113}$, es leído por el matrimonio Wagner el 26 de septiembre con verdadero deleite. Su

103 Marsillach y Lleonart, Joaquín: Ricardo Wagner. Ensayo biográfico crítico con un extenso prólogo epistolar del Dr. D. José de Letamendi. Barcelona, Texidó y Parera, 1878.

104 Marsillach y Lleonart, Joaquín: Ricardo Wagner. Saggio biografico critico di Giachino Marsillach Lleonart. Versione dallo spagnolo e prefazione di Daniele Rubi. Secondo Viaggio nelle región dell'Avenire, note ed appendici del Dott. Filippo Filippi. Coi disegni del Teatro di Bayreuth, ritratto ed autografi di Wagner. Milán, Tip. L. F. Cogliati, 1880. Reimpresión en Milán, L. F. Cogliati, 1881.

105 PeÑa y GoÑI, Antonio: Rienzi: grande ópera trágica en cinco actos. Poesía y música de Ricardo Wagner; versión castellana, precedida de la biografía del célebre maestro por Antonio Peña y Goñi. Madrid, Est. tip. de El Globo, 1875.

106 "Libros presentados a esta redacción por autores o editores", en La Ilustración Española y Americana, XxII/19 (22.05.1878), p. 314.

107 Peña y GoñI, Antonio: "Ricardo Wagner”, en Crónica de la Música, II/48 (21.08.1879, pp. 3-4), 49 (28.08.1879, pp. 3-4), 50 (04.09.1879, p. 3) y 51 (11.09.1879, pp. 2-3).

108 "Wagner", en La Ópera, I/4 (12.09.1878), pp. 26-29.

109 “Algunos datos acerca de la escuela wagneriana”, en La Ópera, I/5 (29.11.1878), pp. 34-37.

110 SCHURÉ, Edouard: Le Drame Musical. París, Sandoz, 1875.

111 Letamend, José de: “Prólogo epistolar", en Marsillach y Lleonard, Joaquín: Ricardo Wagner. Ensayo... op. cit., pp. 11-29.

112 LetAMENDI, José de: "La aparición de Ricardo Wagner deducida de la naturaleza del arte teatral", en Obras Completas. Madrid, Establecimientos Til-Leit de F. Rodríguez Ojeda, 1907, Vol. I, pp. 68-81.

113 Letamend, José de: "Gedanken über die künstlerischen Betrebungen Richard Wagners", en Bayreuther Blätter, 1 (1878), pp. 245-263. 
publicación en la revista wagneriana constituye la mejor prueba de su importancia, junto con la carta de agradecimiento que Wagner escribe a Marsillach esa misma tarde alabando de forma entusiasta el ensayo del profesor de la Universidad Central de Madrid. Cosima anota en su diario que su marido encuentra el ensayo ejemplar -la composición del conjunto, las imágenes, el pensamiento, la ternura de espíritu, el lenguaje ${ }^{114}$ - remitiendo una misiva ${ }^{115}$ que, fechada en Bayreuth y traducida por Marsillach, dice así:

"Señor don Joaquín Marsillach. Estimadísimo amigo:

Mi esposa acaba de leerme la traducción de la carta-prólogo del señor Letamendi a usted: quiso el destino que no me resolviera antes de ahora a proporcionarme este placer.

Con respecto al propio trabajo de usted, siento tener que quedarme por ahora en ayunas; habré de aguardar quizás que se haga una traducción francesa, puesto que yo, con poca aptitud para aprender lenguas extranjeras, no he hallado aún ratos de ocio para tratar de cerca el español, en especial Calderón, Lope de Vega y Cervantes en su idioma original.

En mi modesta librería los tengo, aguardando que llegue la ocasión, que todavía espero, en que me sienta bastante libre para satisfacer mi ardiente deseo de conocer en su peculiar forma de expresión las obras de estos sublimes ingenios, que en la traducción alemana siempre me entusiasmaron. Aunque esto me ha sido imposible hasta el presente, puedo decir a usted que estas traducciones alemanas, por más que desfiguran el original, no dejaron de abrirme -dándome a conocer el espíritu español- un manantial inestimable de profundísima al par que vasta sabiduría. Hasta creo poder asegurar a usted que he penetrado en el espíritu de esos grandes poetas españoles, quizás aún más profundamente que tantos otros como tienen la dicha de haber podido estudiarlos en su lengua nativa.

Lo mismo ha vuelto a sucederme hoy, al conocer a su grande amigo y maestro Letamendi por la traducción alemana de su carta-prólogo: en ésta me está hablando el espíritu del gran Cervantes, del amable Lope. Ningún alemán, ningún francés ni italiano ha podido, en su peculiar forma de conocer y de expresarse, causarme tan hondo y grato sentimiento de admiración como este sabio, sin comparación ilustrado y genial, a quien usted tiene la dicha de llamar «su amigo». No se ofenda usted si le hablo de mi asombro ante esta manifestación, no ya de mero interés, sino de esa que yo llamaría plástica profundidad de Letamendi. La carta de éste a usted, prescindiendo de que a mi se refiere, me da, para mi juicio total del porvenir en el tiempo y en el espacio, una indicación que me complazco en acoger como sublime esperanza del desesperanzado.

¡Benditos seáis vosotros los íberos, a quienes tan lejanos nos figuramos! Que se ensañe el destino contra vosotros, abrasando y consumiendo, abrumando y sofocando, no importa: abrigáis nobles espíritus, y una profunda cultura os defenderá de la falsa civilización y sus monstruosidades, que

114 WaGNER, Cosima: op. cit., pp. 156-157.

115 El texto alemán puede consultarse en JANÉs I NADAL, A: op. cit., p. 60. 
ahora parece haber asignado el dominio intelectual del mundo a las naciones infinitamente menos bien dotadas.

Saludando a usted cordialísimamente le ruego haga sabedor al señor de Letamendi de mi profundo sentimiento de gratitud.

Suyo afectísimo,

Ricardo Wagner"116.

La contraposición de las estéticas wagneriana e italiana en el drama lírico es tratada especialmente en los capítulos segundo y tercero del Ensayo de Marsillach. Dedicado a la relación texto-música, el segundo ${ }^{117}$ censura los libretti de ópera italiana y destaca que Wagner elimina de sus óperas el elemento convencional y las concesiones al espectador, colocando al poema por delante de la música. Asimismo, critica el papel desempeñado por el coro en la ópera italiana y la teoría de Beauquier ${ }^{118}$, según la cual, todo buen libreto "debe estar lleno de situaciones musicales" en las que "los actores pueden prescindir de la acción, detenerse y volver sobre sí mismos para desarrollar la pasión que les anima”, porque, siendo así -comenta Marsillach- el libreto se convierte en "un pretexto para escribir música".

El tercer capítulo, "La Música Teatral"119, censura el predominio de la melodía en la ópera italiana -imponiéndose a libreto, acción, verdad escénica y situaciones- así como el virtuosismo vocal ${ }^{120}$ que interrumpe el desarrollo dramático de la acción, encontrando fuera de lugar, por ejemplo, la muerte de un personaje que, ante la indiferencia de los coros que lo rodean y solamente para la exhibición del cantante, "no acaba de morirse nunca". Asimismo, critica la insistente construcción periódica y simétrica de su melodía, encontrando la repetición de texto y música injustificable, porque su única pretensión es fijarse en la memoria del auditorio para "deleitar el oído y nada más". De ahí deduce Marsillach que el fin de la ópera -basada en la inspiración, pero falta de ciencia- es la música misma; es -dice- "el sensualismo musical", del cual procede, en última instancia, la reiterada utilización de formas tradicionales (recitativo, aria, dúo, terceto, concertante final...) cortadas por el mismo patrón. Un conciso material motívico y las técnicas de la variación y el leitmotiv permiten a Wagner condensar la acción creando "una relación íntima entre las diversas escenas" y, con ayuda de la orquesta, logra crear una admirable red psicológica que revela "los sentimientos ocultos de los personajes cuando la palabra no puede o no debe expresarlos".

En el resto del libro, Marsillach toca dos aspectos que nos interesa destacar: en primer lugar, el foso y la oscuridad de la sala empleados en Bayreuth con el fin de fijar la atención del público, dos peculiaridades que espera se generalicen en todos los teatros ${ }^{121}$; en segundo lugar, las caricaturas, chistes y burlas realizadas sobre Wagner ${ }^{122}$.

116 Marsillach y Lleonart, Joaquín: “A propósito del Lohengrin”, en El Globo, 28.03.1881.

117 Marsillach y Lleonart, Joaquín: "El poema musical”, en Ricardo Wagner. Ensayo..., op. cit., pp. 53-68.

118 Beauquier, Charles: La Musique et le Drame. París, Sandoz et Fischbacher, 1877, p. 43.

119 Marsillach y Lleonart, Joaquín: Ricardo Wagner. Ensayo..., op. cit., pp. 69-98.

120 Marsillach cita el prefacio de Alceste para demostrar que Wagner sigue a Gluck en este aspecto.

121 Marsillach y Lleonart, Joaquín: "El festival de Bayreuth”, en Ricardo Wagner. Ensayo..., op. cit., pp. 99-113.

122 Marsillach y Lleonart, Joaquín: “El porvenir de la música”, en Ricardo Wagner. Ensayo..., op. cit., pp. 114-127. 
Contestando al ensayo de Marsillach, Antonio Fargas y Soler publica en otoño de 1878 unas Observaciones (en vindicación de la ópera italiana) ${ }^{123}$, cuya idea central es la influencia perjudicial de Wagner en la música dramática. La primera parte, una cita de F. Marcillac ${ }^{124}$ y la más interesante, destaca que en el drama musical wagneriano -lo mismo que en la estética de Hegel- están invertidas las relaciones entre música y poema propugnadas por la ópera. No obstante, considera que Wagner no es consecuente con su teoría y que en sus dramas se admira siempre al músico y no al poeta. En este sentido alaba su faceta como orquestador, que, sin embargo, no es suficiente para evitar la fatiga y mantener la atención del oyente durante una representación. Por esta razón -y contradiciendo la teoría wagneriana- admira "la amplia factura, la belleza melódica y la riqueza de colorido instrumental" 125 de los fragmentos sinfónicos escuchados en los conciertos. Asimismo destaca que el desprecio hacia otros compositores, así como el tono altanero, orgulloso, vanidoso y soberbio utilizado por Wagner en sus escritos, han propiciado la reacción de sus adversarios. Por último, explica la existencia de dos tendencias encontradas; una -dice"que puede llamarse melódica o vocal y otra armónica o instrumental: la una que busca los medios de expresión en la belleza y prestigio de la melodía, dando a la voz humana el lugar preferido; la otra que da de barato la melodía y que trata las voces como los instrumentos y la ópera como una especie de sinfonía instrumental y vocal"126.

En la segunda parte de las Observaciones Fargas rebate aisladamente -y página a página- cada una de las aseveraciones del Ensayo de Marsillach con las que se muestra en desacuerdo, de lo que resulta una exposición caótica y lineal de ideas, carente del desarrollo necesario y muy débil en su argumentación, debido en parte a la metodología empleada. No obstante, tratamos de condensar lo más sustancial de su pensamiento. Colocando a la música por delante del poema, Fargas no comparte la idea de Marsillach de que la música sea la decoración y el colorido de las palabras, porque "sería exigir que el arte de los sonidos no hiciese más que un papel secundario en el drama musical" ${ }^{127}$. Si bien es cierto que en la ópera italiana hay un predominio de la melodía, también lo es que en los últimos años había dado mayor variedad a sus formas y concedido más importancia a la armonía y la instrumentación. Por otro lado, no se podría cantar gran parte del libreto si de él se eliminara el elemento convencional, porque en el teatro todo es "pura ficción" y, por tanto, Fargas admite que el moribundo "exprese en un canto más o menos largo entrecortado y repetido, sin faltar a lo verosímil, la congoja de la agonía que puede ser más o menos larga, con tal de que haga sentir al espectador muy profundamente el tránsito de una vida que se extingue, de modo que el fingimiento le parezca una realidad" ${ }^{28}$. Para él la forma de la melodía -sea simétrica, periódica, etc.- carece de importancia, porque sería equivalente a juzgar el mérito de una poesía "por el metro en

123 FARGAS y SOLER, Antonio: Observaciones (en vindicación de la ópera italiana) al Ensayo biográfico-crítico de R. Wagner por D. J. Marsillach Lleonart. Barcelona, Jaime Jepús, 1878.

124 Marcillac, François: Histoire de la Musique moderne et des musiciens célèbres depuis l'Ere cretienn jusqu'a nos jours. París, Sandoz \& Fischbacher, 1876, pp. 191-199.

125 Fargas y Soler, Antonio: op. cit., p. 11.

126 Fargas y Soler, Antonio: op. cit., p. 12.

127 Ibídem, p. 16.

128 Ibídem, p. 19. 
que estuviese compuesta" ${ }^{129}$. Además, la decadencia de la escuela italiana no se debe a que sus principios estéticos sean erróneos, sino a que tras Rossini, Bellini y Donizetti no ha llegado un compositor verdaderamente genial, considerando ampuloso el segundo estilo de Verdi. Pese a todo, el repertorio italiano se sostiene aún en todos los teatros del mundo e incluso en Alemania y, por el contrario, los imitadores de Wagner han fracasado dentro y fuera de Italia, proponiendo como ejemplo el Simone Boccanera de Verdi ${ }^{130}$. Debido a sus opiniones sobre otros compositores consagrados, Wagner ha sido combatido, pero "no insultado", y por la misma razón los antiwagnerianos han ridiculizado su música con la calificación de música del porvenir, que sea, o no, invención de Wagner, es el título de uno de sus escritos ${ }^{131}$. El crítico del Diario de Barcelona concluye sin censurar el prólogo de Letamendi, porque éste -dice- "no vitupera a la escuela italiana, ni habla con desprecio de las producciones de la misma, ni tampoco de sus célebres compositores dramáticos"132.

Marsillach responde en Contrarréplica a las “Observaciones” de D. Antonio Fargas y Soler... ${ }^{133}$, folleto de 47 páginas fechado en Madrid en febrero de 1879 y editado conjuntamente por Antonio de San Martín (Madrid) y Texidó y Parera (Barcelona) en diciembre ${ }^{134}$. Marsillach se confiesa desencantado ante la falta de argumentación de su contrincante, aunque retóricamente dice no poner en tela de juicio su reputación. También se sorprende de su entusiasmo por el libreto italiano, subordinado a la música desde el momento en que los compositores utilizan la misma partitura en situaciones dramáticas completamente diferentes, reutilizando números de unas óperas en otras ${ }^{135}$, de lo que resulta que "los caracteres, las situaciones, el colorido eran para la escuela italiana un mito"136. Marsillach insiste en que el poema, la acción preconcebida y desarrollada con entera independencia, debe fijar el carácter de la música en el drama y, en este sentido, critica "aquella serie de coros, cavatinas, dúos y otros retazos mal zurcidos y peor coordinados, sin acción, incongruentes, metrificados según las reglas de una tradición esterilizante y tiránica" ${ }^{137}$. La decadencia de la escuela italiana es manifiesta porque, exceptuando un escogido número de títulos, el resto han sido olvidados y sustituidos por los de Gounod, Saint-Saëns, Massenet, Berlioz, Rubinstein, Boito y el propio Wagner, de quien repasa los estrenos de El Holandés errante y Tannhäuser en Europa y América, como prueba de que es un repertorio aceptado. Sorprendido ante la afirmación de que Wagner no ha sido insultado, Marsillach escoge algunos de la larga lista de términos utilizados para burlarse del compositor, muchos recogidos en el Diccionario-léxico wagneriano de mala educación, que contiene las expresiones despreciativas, rencorosas, groseras y

129 Ibídem, p. 22.

130 Ibídem, pp. 25-26.

131 Ibídem, p. 30.

132 Ibídem, p. 36.

133 Marsillach y Lleonart, Joaquín: Contrarréplica a las “Observaciones” de D. Antonio Fargas y Soler en vindicación de la ópera italiana por Joaquín Marsillach y Lleonart representante de la Patronatverein de Bayreuth. Barcelona, Imp. de la Renaixensa, 1879.

134 "Noticias varias”, en Crónica de la Música, I/66 (25.12.1879), p. 4.

135 Marsillach propone numerosos ejemplos de Rossini, Bellini y Verdi.

136 Marsillach y LleOnART, Joaquín: Contrarréplica..., op. cit., p. 15.

137 Ibídem, p. 18. 
calumniosas que se han empleado contra el maestro R. Wagner, sus obras y sus discípulos por sus enemigos y detractores, reunidas en horas de ociosidad para esparcimiento del ánimo ${ }^{138}$. Citando el mismo pasaje utilizado por Peña y Goñi en su polémica con Barbieri, Marsillach corrige a Fargas sobre la autoría de la expresión música del porvenir y, al mismo tiempo, pide que la crítica se centre en la obra de Wagner y no en su carácter porque -dice Marsillach- "al fin y al cabo, en las circunstancias por que él ha pasado muy pocos hubieran procedido de distinta manera" ${ }^{139}$. Concluida la Contrarréplica, Fargas escribe un nuevo artículo ${ }^{140}$ que obliga a Marsillach a realizar un "Post-Scriptum", donde expresa su deseo de no continuar la discusión, ya que considera que sus polémicas "no reportan provecho para el Arte ni lucimiento personal" ${ }^{\prime 14}$.

Antes de concluir el año, Fargas escribe Contestación a la Contrarréplica ${ }^{142}$, lamentando que Marsillach encuentre vacío de argumentos su escrito anterior y aconsejándole mayor mesura y cortesía. Fargas insiste en que la música de Wagner es más "tolerable" cuando se interpreta como arreglo instrumental en los conciertos y, por tanto, desposeída de sus connotaciones dramáticas, es decir, como música pura. También en que su influencia ocasionará un retroceso de la música dramática, porque, no dándose el improbable caso de poseer el mismo talento que Wagner, sus imitadores caerán en la parodia y el ridículo. La limitada recepción de su obra fuera de Alemania -a groso modo, su estilo intermedio- no habría sido posible sin la publicación previa de sus teorías y la audición de fragmentos en concierto, prueba de que Wagner no es un verdadero genio. En este sentido, Fargas recuerda su mala acogida en Francia y el dudoso éxito de las representaciones en Italia, mientras la ópera italiana sigue vigente en los teatros de Europa y América. Sobre la reutilización de música en la ópera italiana, considera que los ejemplos citados por su contrincante son excepciones "insuficientes para deducir y aseverar que los caracteres, las situaciones y el colorido eran un mito para la escuela italiana"143. Tras justificar los insultos a Wagner, en la misma medida en que éste los prodiga a Rossini, Fargas reitera que el alemán es el creador de la expresión música del porvenir porque, en su opinión, equivale a obra de arte del porvenir. La influencia de Meyerbeer -y no la de Wagner- está detrás del enriquecimiento armónico e instrumental experimentado en la ópera italiana ${ }^{144}$, un género destacado como el principal responsable de la generalización del gusto musical en el mundo ${ }^{145}$. Encontrando el wagnerismo excesivamente intransigente, radical e intolerante, Fargas se declara ecléctico y concluye el escrito proponiendo como último argumento de su verdad su experiencia y madurez.

138 TAPPERT, Wilhelm: Ein Wagner lexicon. Leipzig, E. W. Fritzsch, 1877.

139 Marsillach y Lleonart, Joaquín: Contrarréplica..., op. cit., p. 41.

140 Firmado bajo el pseudónimo de Antonio Fajas y Ferrer, apareció en La Academia, 07.12.1878.

141 Marsillach y Lleonart, Joaquín: Contrarréplica..., op. cit., p. 47.

142 FARgas y Soler, Antonio: Contestación a la Contrarréplica de D. Joaquín Marsillach y Lleonart a mis Observaciones en vindicación de la ópera italiana. Barcelona, Imprenta Barcelonesa, 1879.

143 Fargas y Soler, Antonio: Contestación..., op. cit., p. 11.

144 Ibídem, pp. 19-20.

145 Ibídem, p. 24. 


\section{CONCLUSIÓN}

En la década de 1860 la crítica musical plantea una antítesis entre la ópera y el drama musical wagneriano, pero las polémicas como tales no se producen en nuestro país hasta la década de 1870. Éstas están motivadas no sólo por la discusión estética, sino también por otras problemáticas relacionadas a veces con el debate conservadurismo-progresismo, sirviendo asimismo de catalizador de intereses editoriales, enfrentamientos nacionalistas, rencillas personales y choques generacionales. Al señalar las fechas de nacimiento, este último aspecto se manifiesta tímidamente en la polémica de Piqué y Cerveró (*1817) con Pujol Fernández (*1831), se hace más evidente en las mantenidas por Barbieri (*1823) con Peña y Goñi (*1846) y Chapí (*1851) y se agudiza, de manera acusada, en la sostenida entre Fargas y Soler (*1813) y Marsillach (*1859). Debido, en buena medida, a que uno de los temas más discutidos es el controvertido carácter del compositor, las querellas desaparecen tras la muerte de Wagner en 1883, siendo explícita la petición realizada por Pedrell para que cesen las hostilidades ${ }^{146}$, aunque esto no quiere decir que después de esta fecha la crítica no siga ocupándose de la conveniencia o no de su sistema.

Recibido: 12/03/2010

Aceptado: 03/06/2011

146 Pedrell, Felipe: “Tregua a la posteridad”, en Notas Musicales y Literarias, II/31 (01.03.1883), p. 2. 